This is the final peer-reviewed accepted manuscript of:

Pistocchi, Rossella: Modeling of photosynthesis and respiration rate for Isochrysis galbana (T-Iso) and its influence on the production of this strain. BIORESOURCE TECHNOLOGY 203. 0960-8524

DOI: $10.1016 /$ j.biortech.2015.12.050

The final published version is available online at:

http://dx.doi.org/10.1016/j.biortech.2015.12.050

Rights / License:

The terms and conditions for the reuse of this version of the manuscript are specified in the publishing policy. For all terms of use and more information see the publisher's website.

This item was downloaded from IRIS Università di Bologna (https://cris.unibo.it/)

When citing, please refer to the published version. 


\title{
Modeling of photosynthesis and respiration rate for Isochrysis galbana (T-Iso) and its influence on the production of this strain
}

\author{
Davide Ippoliti a , Cintia Gómez ${ }^{\text {b,c }}$, María del Mar Morales-Amaral ${ }^{\text {b,c }}$, Rossella Pistocchi ${ }^{\text {a }}$, \\ J.M. Fernández-Sevilla ${ }^{\text {b,c }}$, F. Gabriel Acién ${ }^{\text {b,c,* }}$ \\ ${ }^{a}$ Dpt Biological, Geological and Env. Sciences, Univ. Bologna, 48123 Ravenna, Italy \\ ${ }^{\mathrm{b}}$ Department of Chemical Engineering, University of Almería, 04120 Almería, Spain

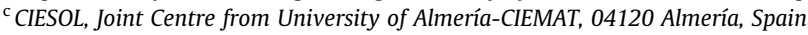

\section{H I G H L I G H T S}

- Photosynthesis rate of Isochrysis galbana T Iso is modeled.

- Respiration rate of Isochrysis galbana T Iso is modeled.

- Major factors reducing the performance of microalgae cultures are identified.

- Model demonstrate that the productivity can be doubled at real conditions.

\section{A R T I C L E I N F O}

Keywords:

Microalgae

Modeling

Photosynthesis rate

Respiration rate

Photobioreactors

\begin{abstract}
A B S T R A C T
Isochrysis galbana is a widely used strain in aquaculture in spite of its low productivity. To maximize the productivity of processes based on this microalgae strain, we have developed a model considering the influence of irradiance, temperature, $\mathrm{pH}$ and dissolved oxygen concentration on the photosynthesis and respiration rate. Results demonstrate that this strain tolerates temperatures up to $35^{\circ} \mathrm{C}$ but it is highly sensitive to irradiances higher than $500 \mu \mathrm{E} \mathrm{m}{ }^{2} \mathrm{~s}^{1}$ and dissolved oxygen concentrations higher than $11 \mathrm{mg} \mathrm{l}^{1}$. We have validated the developed model using data from an industrial scale outdoor tubular photobioreactor demonstrating that inadequate temperature and dissolved oxygen concentrations reduce productivity to half that which is maximal, according to light availability under real outdoor conditions. The developed model is a useful tool for managing working processes, but especially in the development of new processes based on this strain and to take decisions regarding optimal control strategies.
\end{abstract}

\section{Introduction}

Over recent decades, interest in microalgae has grown enormously. In particular, these organisms are used in the production of chemicals, dietary supplements, and in the aquaculture sector (Muller Feuga, 2013). With an expanding aquaculture industry, the demand for live microalgae is also increasing. Therefore, their use as food in aquaculture remains the major reason for their production. Several strains belonging to the genus Isochrysis (Prymnesiophyceae) are among the most widely used microalgae in aquaculture. Isochrhysis aff. galbana Green 'Tahiti' (T Iso) is one

* Corresponding author at: Department of Chemical Engineering, University of Almería, Carretera Sacramento s/n, E04120 Almería, Spain. Tel.: +34 950015443; fax: +34950015484.

E-mail address: facien@ual.es (F.G. Acién). of most commonly used strains because of its biochemical profile (fatty acids, ascorbic acid, etc.) (Muller Feuga, 2013). T Iso is supposed to be an excellent candidate for mass culture because of its ability to adapt to a wide range of temperatures and photon flux densities (Saoudi Helis et al., 1994; Marchetti et al., 2012).

Traditional microalgae production in aquaculture represents one of the main problems in the development of a number of processes due to the typically low productivity and poor quality of the resulting biomass, along with contamination and high production costs (Muller Feuga, 2013; Boeing, 2000). The microalgal production systems used by fish farmers are normally simple and traditional with few, if any, control systems, but this is expensive and leads to variable microalgal biochemical composition. Optimization of microalgal culture conditions is therefore necessary to reduce production costs and meet the demand of hatchery managers for an easy, cheap and reliable method of producing 
microalgae of high nutritional value. Continuous and semicontinuous culture is an attractive alternative to batch production. The advantage of closed photobioreactors (PBRs), as compared to open ponds or tanks, is that the light path length is noticeably reduced leading to higher cell densities, which diminishes the chance of contamination and facilitates harvesting. Furthermore, cultures inclosed PBRs do not suffer from severe evaporative losses, while temperature, $\mathrm{pH}$ and growth condition can be more easily controlled. It is therefore possible to improve the production and quality of the resulting biomass and reduce the production costs (Norsker et al., 2011; Acién et al., 2013a,b).

Whatever the reactor used, outdoor photobioreactors are subject to daily variations in culture parameters that influence their overall yield (Camacho et al., 1999; van Bergeijk et al., 2010; Mendoza et al., 2013; Fernández et al., 2014). In order to adequately design outdoor photobioreactors, it is necessary to know the influence of culture conditions on the photosynthesis rate as a primary step in determining the biomass productivity of any photosynthetic system. The utilization of average variable values, whether daily or weekly, only provides partial information. Greater accuracy can be obtained by using instantaneous variable values, and models which take into account the rapid response of microal gae cells to culture condition variations (Costache et al., 2013). There are already publications on models that describe the photosynthetic response to environmental changes under nutrient unlimited culture conditions such as irradiation, temperature, $\mathrm{pH}$ and dissolved oxygen. The photosynthesis rate has been reported as increasing hyperbolically with irradiance up to values above which it decreases due to photoinhibition. Researchers have devel oped several models on irradiation (Platt et al., 1980; Eilers and Peeters, 1988; Papadakis et al., 2005; Bernard and Rémond, 2012). Another important factor influencing photosynthesis is temperature, and the models produced up to now have been able to describe the most optimal condition of growth and productivity (Bernard and Rémond, 2012; Ras et al., 2013; Guedes et al., 2011; Bitaubé et al., 2008). Less information has been reported on the influence of $\mathrm{pH}$ or dissolved oxygen on the microalgae photosyn thesis rate. Large variations in $\mathrm{pH}$ can reduce microorganism pro ductivity (Camacho et al., 1999; Ying et al., 2014; Cabello et al., 2015); but these values remain almost stable (7.5 8.0) in closed tubular photobioreactors because of the on demand injection of $\mathrm{CO}_{2}$. Conversely, in this type of photobioreactor, the high concen tration of dissolved oxygen can increase considerably (Camacho et al., 1999; Acién et al., 2013a). Several studies reported dissolved oxygen concentrations as high as $500 \%$ Sat. causing photosynthesis inhibition and eventually leading to culture death (Mendoza et al., 2013). In addition, it can be useful to observe and to model the res piration trend to understand how, and how much, this activity influences photosynthesis with accurate values of net photosyn thesis being obtained by adding the values for oxygen consumed during the dark period to the oxygen production during the light period.

In this paper, we studied the influence of major environmental parameters (irradiance, temperature, $\mathrm{pH}$ and dissolved oxygen) on determining the net photosynthesis and the respiration rates of Isochrysis galbana. The results were used to develop an overall model that allows the simulation of the net photosynthesis and respiration rates under different culture conditions. The model was validated by experimental data assembly obtained under dif ferent culture conditions to those tested. Furthermore, the model was used to simulate the daily behaviour of outdoor cultures per formed in tubular photobioreactors, thus verifying their validity. According to these results, the developed model is a useful tool to optimize $\mathrm{T}$ PBRs design and operation. In addition, the method used to construct this model is applicable to other strains allowing us to optimize microalgae based processes.

\section{Methods}

\subsection{Microorganisms and culture conditions}

The strain used, Isochrysis aff. galbana (T Iso), was obtained from the Universidad de Santiago de Compostela. Stock cultures were maintained photoautotrophically in spherical flasks (1.0 l capacity) using Algal medium (Bionova, Santiago de Compostela, Spain). The inoculum was maintained with aeration and an on demand $\mathrm{CO}_{2}$ supply under continuous illumination at $100 \mu \mathrm{E} \mathrm{m}^{2} \mathrm{~s}^{1}$, at $25^{\circ} \mathrm{C}$.

For the experiments, the inoculum was transferred to laboratory scale tubular photobioreactors and to industrial scale outdoor tubular photobioreactors (T PBRs). Details of the reactors used are next provided.

\subsection{Laboratory photobioreactors}

To simulate the environmental conditions prevailing into the cultures performed in outdoor T PBRs, an indoor system simulating outdoor conditions was developed. Thus, laboratory culture was performed in a stirred tank reactor made with a section of the same polymethylmethacrylate (PMMA) tube that used in out door T PBRs ( $0.09 \mathrm{~m}$ diameter, $0.5 \mathrm{~m}$ high, $0.8 \mathrm{~L}$ capacity), only by covering one of the extremes. The reactor thus build up was inoc- ulated with $20 \%$ of the volume of inoculum and completing with fresh Algal medium. Then, it was operated in batch mode to achieve a biomass concentration higher than $1.0 \mathrm{~g} / \mathrm{l}$, next it being operated in semicontinuous mode, by replacing $20 \%$ of the culture volume daily with fresh medium, till the steady state is reached, after 10 days. The reactor was magnetically stirred to simulate the mixing existing in outdoor T PBRs. Concerning illumination, the reactor was illuminated artificially by one side simulating the solar cycle, using four Philips PL 32 W/840/4p white light lamps, with a

maximal irradiance of $1000 \mu \mathrm{E} \mathrm{m}^{2} \mathrm{~s}^{1}$ (measured in the center of the reactor when empty). The light lamps used mainly provide disperse radiation, but because lamps were only located in one side of the reactor the light distribution approaches that found inside the greenhouse where the outdoor T PBRs are located. The $\mathrm{pH}$ was controlled by on demand injection of pure $\mathrm{CO}_{2}$ at $\mathrm{pH}$ 8.0. Whereas the temperature was controlled by regulating the air temperature in the chamber on which the reactor was located. The culture temperature modifies along the day, ranging from $30{ }^{\circ} \mathrm{C}$ during the simulated noon to $25^{\circ} \mathrm{C}$ during the simulated night, average daily temperature of the culture being $28 \pm 3^{\circ} \mathrm{C}$. On the reactor the dissolved oxygen concentration was maintained lower than $200 \%$ Sat. by the on demand injection of air into the reactors, also to simulate the conditions prevailing in outdoor T PBRs.

\subsection{Outdoor photobioreactors}

Outdoor cultures were performed in industrial T PBRs of $3.0 \mathrm{~m}^{3}$ capacity. The microalgal production facility used is situated inside a greenhouse at the "Estación Experimental Las Palmerillas", which belongs to Fundación CAJAMAR (Almería, Spain). The facility consists of ten tubular fence type photobioreactors built as previously described (Fernández et al., 2014). Each photobioreactor is made of a $400 \mathrm{~m}$ long PMMA tube, $0.09 \mathrm{~m}$ in diameter, with a bubble column (3.5 $\mathrm{m}$ high and $0.4 \mathrm{~m}$ in diameter) for degassing and heat exchange. The $\mathrm{pH}$, temperature and dissolved oxygen at the end of the loop are measured using Crison probes (Crison Instruments, Spain), connected to an MM44 control transmitter unit (Crison Instruments, Spain), in turn connected to a PC control unit, allow ing complete monitoring and control of the facility. Each reactor is bubbled at a constant airflow rate of $2001 \mathrm{~min}^{1}$, whereas the $\mathrm{pH}$ is 
controlled by on demand injection of pure $\mathrm{CO}_{2}$ at $31 \mathrm{~min}{ }^{1}$. The culture temperature is controlled by passing cooling water at $1500 \mathrm{lh}^{1}$ (when needed as determined by the computer control) through an internal heat exchanger located in the bubble column of each photobioreactor. The reactor was operated in continuous mode by harvesting $20 \%$ of the culture volume daily, which was then replaced by fresh medium. The culture medium was prepared online using a fertigation unit with a $4 \mathrm{~m}^{3} \mathrm{~h}{ }^{1}$ capacity. The culture medium was sterilized prior to introduction into the PBRs during the daylight period. The $\mathrm{pH}, \mathrm{DO}$, temperature in each PBR, and radiation inside the greenhouse and inside the laboratory were recorded daily. The data capture system and control software (developed in DaqFactory 5.0, Azeotech Inc.) controlled and monitored all activities in the facility.

\subsection{Measurement of photosynthesis and respiration rate}

Photosynthesis and respiration measurements were performed in specifically designed equipment, by measuring the variation of dissolved oxygen concentration under controlled conditions. For this, samples from steady state culture on the laboratory photobioreactor were taken and diluted to $0.15 \mathrm{~g} \mathrm{l}^{1}$ to achieve a diluted culture. The samples were placed in a $100 \mathrm{ml}$ cylindrical stirred glass chamber (0.04 $\mathrm{m}$ diameter, $0.10 \mathrm{~m}$ height), in which irradiance (QSL 1000, Walz, Germany), temperature (pt 100), pH (Crison 5343, Barcelona, Spain) and dissolved oxygen (Crison 5002, Barce lona, Spain) probes were located. The irradiance sensor was located in the center of the glass chamber whereas the other sensors were located close to the surface to avoid shadows into the system. To illuminate the system two sets of four fluorescent lamps (Osram 80 $\mathrm{W}$ ) were placed at right and left of the glass chamber, the intensity of the lamps being automatically regulated to obtain the desired irradiance inside the center of the chamber once the sam ple was added. Due to the utilization of diluted cultures, both side illumination and the short light path of the sample chamber used, the maximum deviation of irradiance at which the cells are exposed to into the system was $10 \%$. Each sample was subjected to repeated 5 min light dark periods for a maximum of $30 \mathrm{~min}$ to measure and register the variation of culture parameters (dis- solved oxygen, $\mathrm{pH}$ and temperature) under whichever conditions. The entire system was computer controlled using DaqFactory soft ware. Data allow us confirming that during measurements no rel- evant variations of temperature or $\mathrm{pH}$ take place, whereas dissolved oxygen variations allows calculating the photosynthesis and respiration rate. Gross photosynthesis rate was calculated from slope of dissolved oxygen accumulation during light period, whereas respiration rate was calculated from slope of dissolved oxygen accumulation during dark period, net photosynthesis rate being calculated as the sum of both gross photosynthesis and res- piration rate to include respiration performed during light period. Three consecutive measurements were performed to obtain mean values of photosynthesis and respiration rates.

Photosynthesis and respiration rate of samples exposed to different irradiancies inside the glass chamber were measured. Moreover experiments were performed also modifying the $\mathrm{pH}$ of the samples. For this the $\mathrm{pH}$ of fresh medium used to dilute the sample from the laboratory photobioreactor was adjusted by adding $\mathrm{HCl}$ or $\mathrm{NaOH}$, to desired value then the photosynthesis and respiration rate of final diluted sample being measured. Concerning temperature a similar strategy was used, the temperature being adjusted by using cold or warm culture medium to dilute the sample. Finally experiments were performed modifying the dissolved oxygen by bubbling pure oxygen or pure nitrogen into the fresh medium solution used to dilute the sample. For each measurement a new sample from the laboratory photobioreactor in steady state was used, to avoid accumulation of effects.

\subsection{Biomass concentration}

Either for laboratory or outdoor cultures the microalgal biomass concentration was measured by dry weight measurements. For this, $50 \mathrm{~mL}$ aliquots of the cell suspension were filtered through 0.7 $\mu \mathrm{m}$ Millipore filter paper, washed with $30 \mathrm{~mL}$ of ammonium formate, and the filters containing the algae were dried in an oven at $80^{\circ} \mathrm{C}$ for $24 \mathrm{~h}$.

\subsection{Software}

DaqFactory (Azeotech, USA) was used to control the photobioreactors. Statistical analysis of the data was carried out using the Statgraphics Centurion XVI software package. Analysis of vari ance (ANOVA) was used to evaluate the influence of each of the variables studied on the photosynthesis and respiration rate. Non linear regression was used to fit experimental data to the proposed models and to determine characteristic parameter values. Microsoft Excel was used to perform simulations using the developed models.

\section{Results and discussion}

\subsection{Photosynthesis and respiration rate models}

Microalgae productivity is influenced by various factors but under unlimited nutrient conditions, the most important are irradiance, temperature, $\mathrm{pH}$ and dissolved oxygen. To optimize the productivity of whichever strain in real scale reactors, the most accurate method is to expose it to different conditions directly in industrial scale photobioreactors. However, this would require high costs and a long time. Alternatively, the influence of these factors can be studied in the laboratory simulating outdoor conditions to develop models that must subsequently be verified outdoors; most of these models analyse the production of oxygen (photosyn thesis and respiration) as the first step in the biomass production process (Costache et al., 2013; Yun and Park, 2003; Vejrazka et al., 2013), this was the method used in the present work. There fore, to modeled the response of $I$. galbana cells to environmental factors, experiments were performed measuring the oxygen production rate under light conditions and the respiration rate under dark conditions, with controlled environmental variables. These measurements allowed us to calculate the cells' net photosynthesis from the difference between these two measurements. Samples were collected from laboratory cultures operated in indoor continuous mode but simulating outdoor conditions to maximize the applicability of the developed models. Thus, experimental values of biomass concentration and productivity measured indoors were close to those measured outdoors, ranging from 0.6 to 0.9 gbiomass $1^{1}$ and from 0.2 to 0.3 g biomass ${ }^{1}$ day ${ }^{1}$. These values are higher than those previously reported for this strain under outdoor conditions of $0.075 \mathrm{~g} \mathrm{l}^{1}$ day ${ }^{1}$ in tubular photobioreac tors (van Bergeijk et al., 2010) and $0.13 \mathrm{~g} \mathrm{l}^{1}$ day ${ }^{1}$ in flat panels (Zhang and Richmond, 2003), thus verifying the adequacy of the culture conditions. Moreover, this strategy validates the experi ments themselves and their applicability in simulating real outdoor cultures.

Concerning irradiance, it was observed that the net photosynthesis rate was zero at zero irradiance and increased with irradiance up to values of $565 \mathrm{mgO}_{2} \mathrm{~g}_{\text {biomass }} \mathrm{h}{ }^{1}$ at an irradiance of $600 \mu \mathrm{E} \mathrm{m}{ }^{2} \mathrm{~s}^{1}$, then decreased due to photo inhibition to 394 $\mathrm{mgO}_{2} \mathrm{~g}_{\text {biomass }} \mathrm{h}{ }^{1}$ at an irradiance of $2000 \mu \mathrm{E} \mathrm{m}{ }^{2} \mathrm{~s}^{1}$ (Fig. $1 \mathrm{~A}$ ). According to these data, the photosynthesis rate is maximal at an irradiance ranging from 500 to $1000 \mu \mathrm{E} \mathrm{m}{ }^{2} \mathrm{~s}^{1}$. Furthermore, it is confirmed that this strain is less tolerant to high irradiance than 

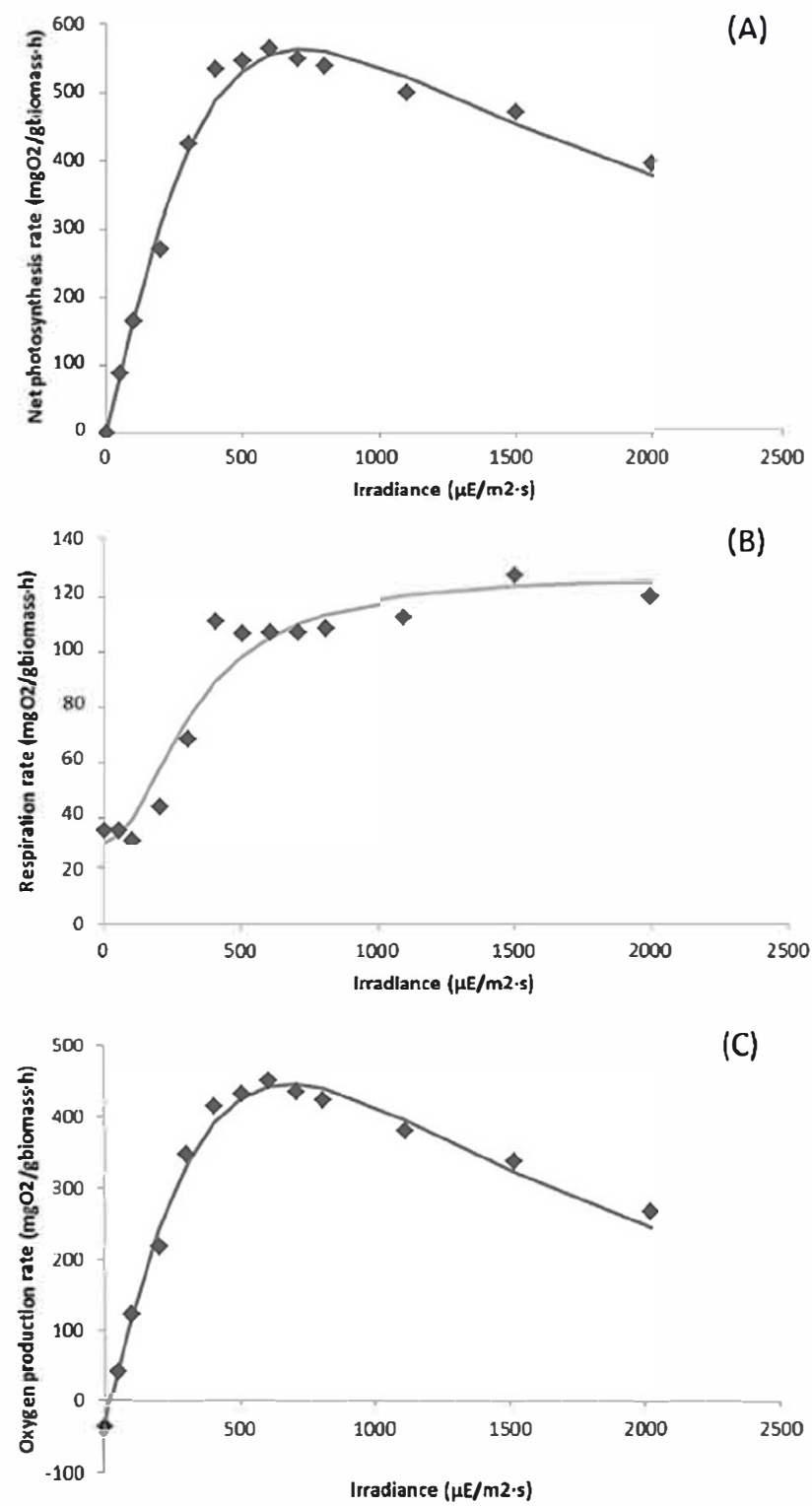

Fig. 1. Influence of irradiance on the net photosynthesis (A), respiration (B) and oxygen production rate $(\mathrm{C})$ of Isochrysis galbana at $29^{\circ} \mathrm{C}, \mathrm{pH}=7.5$ and $\mathrm{DO}_{2}=7.6 \mathrm{mg} /$. Lines correspond to fit the proposed models (Eqs. (1) and (2))

other commercial strains such as Haematococcus pluvialis, Chlorella vulgaris and Scenedesmus almeriensis (Costache et al., 2013; Yun and Park, 2003; Jeon et al., 2006). Nevertheless, the maximum daily irradiance to which the T PBRs were exposed during this research (April to June) ranged from 600 to $900 \mu \mathrm{Em}{ }^{2} \mathrm{~s}^{1}$, within the experimentally determined optimal value range. Conceming respira tion, at zero irradiance the respiration rate was $37 \mathrm{mgO}_{2} \mathrm{~g}_{\text {bionass }} \mathrm{h}{ }^{1}$. increasing with irradiance up to $111 \mathrm{mgO}_{2}$ gbiomass $\mathrm{h}^{1}$ at an irradi ance of $400 \mu \mathrm{E} \mathrm{m}{ }^{2} \mathrm{~s}^{1}$, then remaining constant whatever the irradiance in the range tested (Fig. 1B). This upward trend in the respiration rate is also confirmed by other strains such as Coelastrum sphaericum and Scenedesmus falcatus (Grobbelaar and Soeder, 1985). The oxygen production rate is the difference between these two parameters, representing the production of oxygen under light conditions, which is proportional to the biomass production rate. The data demonstrated that the oxygen production rate is negative under dark conditions, with an irradi ance level equal to $15 \mu \mathrm{E} \mathrm{m}{ }^{2} \mathrm{~s}^{1}$ being necessary to achieve an oxygen production rate equal to zero (the compensation point)
(Fig. 1C). At an irradiance higher than $15 \mu \mathrm{E} \mathrm{m}{ }^{2} \mathrm{~s}^{1}$, the net pho tosynthesis rate is much higher than the respiration rate, thus the oxygen production rate fits to the behaviour observed for the net photosynthesis rate. According to these results, the maximal respiration rate is $20 \%$ of the maximal photosynthesis rate; this ratio being strain specific (Geider and Osbome, 1989). From these data it could be concluded that the net photosynthesis rate can be fitted to the Eiler and Peters model (Eq. (1)) (Eilers and Peeters, 1988) whereas the respiration rate can be fitted to the hyperbolic model with no inhibition (Eq. (2)).

$\mathrm{PO2}(I) \frac{I}{a \cdot l^{2}+b \cdot I+c}$

$\mathrm{RO} 2(I) \quad \mathrm{RO} 2 \mathrm{~min}+\frac{\mathrm{RO} 2 \mathrm{max} \cdot I^{\underline{n}}}{I k^{n}+I^{n}}$

The response of the net photosynthesis rate to irradiance is modulated by other environmental conditions such as temperature, $\mathrm{pH}$ and dissolved oxygen. The experiments carried out allow us to calculate the normalized net photosynthesis rate as a function of these culture conditions. Data show that temperature and $\mathrm{pH}$ exhibit similar behaviour, with the net photosynthesis rate being zero at $12{ }^{\circ} \mathrm{C}$ and $\mathrm{pH} 3$, increasing to a maximum of $36{ }^{\circ} \mathrm{C}$ and $\mathrm{pH} \mathrm{7.5,} \mathrm{then} \mathrm{decreasing} \mathrm{to} \mathrm{zero} \mathrm{at}$ maximum values of $45^{\circ} \mathrm{C}$ and $\mathrm{pH} 10$ (Fig. 2A, B). It is unexpected that the optimal tempera ture for maximizing the photosynthesis rate is close to $36{ }^{\circ} \mathrm{C}$. This temperature is high when compared to previously reported opti mal temperatures for this strain, ranging from $25^{\circ} \mathrm{C}$ to $30^{\circ} \mathrm{C}$ (Marchetti et al., 2012; Renaud et al., 2002; Claquin et al., 2008). Regarding the $\mathrm{pH}$, tolerance to this parameter is different for each strain. For most microalgae growth it is optimal at $\mathrm{pH}$ values between 7.0 and 8.0; however for others such as Spirulina, alkaline $\mathrm{pH}$ is recommended; $\mathrm{pH}$ has even been reported as useful in con trolling contaminants in mixed cultures (Goldman et al., 1982). Regarding the dissolved oxygen concentration, the net photosynthesis rate is maximal at dissolved oxygen concentrations from zero to $11 \mathrm{mg} \mathrm{l}{ }^{1}$, then exponentially decreases to zero at $20 \mathrm{mg} \mathrm{I}{ }^{1}$ due to oxygen inhibition (Fig. 2C). It's important to note that this is a relevant parameter because oxygen is produced during photo synthesis and can accumulate in high concentrations in closed photobioreactors, reducing the photosynthesis rate and favouring culture photorespiration (Mendoza et al., 2013). Therefore, in high dissolved oxygen concentrations, photorespiration takes place; the oxygen binds to the Rubisco enzyme and modifies its role from car boxylase to oxygenase, reducing carbohydrate synthesis (Badger et al., 2000). Variation in the normalized net photosynthesis rate with temperature and $\mathrm{pH}$ can be fitted to the cardinal model devel oped for bacteria (Rosso et al., 1993) and validated for microalgae (Bemard and Rémond, 2012). The cardinal model is a simple equation considering a maximum, a minimum and an optimal value, the values of the variable only existing on the range between max imum and minimum tolerable values, with a Gaussian form. This equation allows representing the behaviour of several biological processes. According to this model, the net photosynthesis rate is a function of the difference between the variables (temperature, $\mathrm{pH}$ ) and the characteristic values of the strain (maximal, minimal and optimal), defined only in the range of tolerable values. Other authors proposed models based on the Arrhenius equation (Costache et al., 2013; Bitaubé et al., 2008) or a non linear correla tion (Blanchard et al., 1996; Moisan et al., 2002) to consider the influence of temperature on the microalgae cultures. Thus, Eqs.( 3 ) and (4) allow us to modeled the response of the net photosyn thesis rate to temperature and $\mathrm{pH}$ according to the cardinal model (Bemard and Rémond, 2012). A model considering inhibition 
by product, as previously reported (Costache et al., 2013) can be used to model the response to dissolved oxygen concentration (Eq. (5)) whose performance modifies as a function of exposure time. To determine the "validity time" of the model, it is necessary to evaluate the tolerance of $I$. galbana cells to more adverse culture conditions. From the experimental data, the most unexpected value was

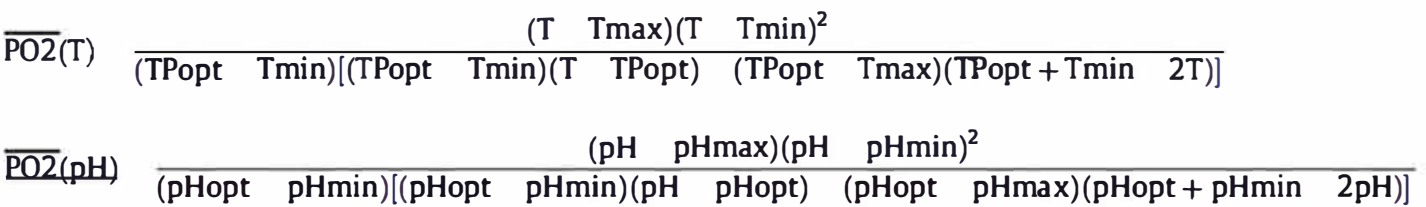

$$
\overline{\mathrm{PO} 2}(\mathrm{DO2}) 1\left(\frac{\mathrm{DO} 2}{\mathrm{DO2max}}\right)^{m}
$$

An analogous study was performed concerning the respiration rate. The variation in the normalized respiration rate with the tem perature, pH and dissolved oxygen shows the same behaviour (Fig. 3 ), which was analogous to that previously observed for the variation in the net photosynthesis rate with temperature and $\mathrm{pH}$. The respiration rate was zero at values of $12^{\circ} \mathrm{C}, \mathrm{pH} 3$ and $0 \mathrm{mg} \mathrm{I}{ }^{1}$, but it increased with the temperature, $\mathrm{pH}$ and dissolved oxygen to be maximal at $32{ }^{\circ} \mathrm{C}, \mathrm{pH} 7.5$ and $16 \mathrm{mg} \mathrm{l}{ }^{1}$, then decreased to zero at maximal values of $46^{\circ} \mathrm{C}, \mathrm{pH} 10$ and $26 \mathrm{mg} l^{1}$. The influence of temperature and $\mathrm{pH}$ on the respiration rate is related to the adequacy of the culture conditions to the optimal ones required by the strain, whereas the influence of dissolved oxygen concentration is related to the nutrient availability or excess; in this case, the dissolved oxygen required for respiration. According to these results, the variation in the nomalized respira tion rate to changes in temperature or $\mathrm{pH}$ agree with the previously reported cardinal model, whereas the influence of dis solved oxygen can be modeled using nutrient limitation inhibition models. However, because the cardinal model also reproduces the observed pattem, and to reduce the variety of the equations used, this cardinal model has also been employed to model the influence of dissolved oxygen on the respiration rate. Thus, the following equations are used to model the respiration rate's response to temperature (Eq. (6)), pH (Eq. (7)) and dissolved oxygen (Eq. (8)). the optimal temperature of $36^{\circ} \mathrm{C}$. It is possible that although the photosynthesis rate increases with temperature over a short per iod, over longer periods other adverse effects occur at such a tem perature and, thus, the overall performance of the cells diminishes. To study the model validity time, a culture was continuously exposed to a temperature of $36^{\circ} \mathrm{C}$, samples being taken at different times to study the variations in the photosynthesis and respiration rates over time. Data show that the net photosynthesis rate was stable for at least $100 \mathrm{~min}$, then slightly decreased after $150 \mathrm{~min}$ (Fig. 4A), thus confirming the tolerance of this strain to high tem peratures for a maximal two hour period. Regarding the respira tion rate, it was constant the whole time, there was no observable tendency for exposure time to high temperature (Fig. 4B). Because the net photosynthesis rate was much higher than the respiration rate under the standard conditions used, the oxygen production rate behaved similarly to that discussed for the net photosynthesis rate (Fig. 4C).

According to these results, the net photosynthesis and respira tion rates can be modeled by combining these equations to obtain a general equation representing the overall strain behaviour based on the observed patterns. Thus, Eqs. (9) and (10) allow us to mod eled the net photosynthesis and respiration rates as a function of the culture conditions (irradiance, temperature, $\mathrm{pH}$ and dissolved oxygen) to which the cells are exposed

$\mathrm{PO} 2 \mathrm{PO} 2(I) \cdot \overline{\mathrm{PO} 2(\mathrm{~T})} \cdot \overline{\mathrm{PO} 2(\mathrm{pH})} \cdot \overline{\mathrm{PO} 2(\mathrm{DO} 2)}$

$\mathrm{RO} 2 \mathrm{RO} 2(I) \cdot \overline{\mathrm{RO} 2(\mathrm{~T})} \cdot \overline{\mathrm{RO} 2(\mathrm{pH})} \cdot \overline{\mathrm{RO} 2(\mathrm{DO} 2)}$

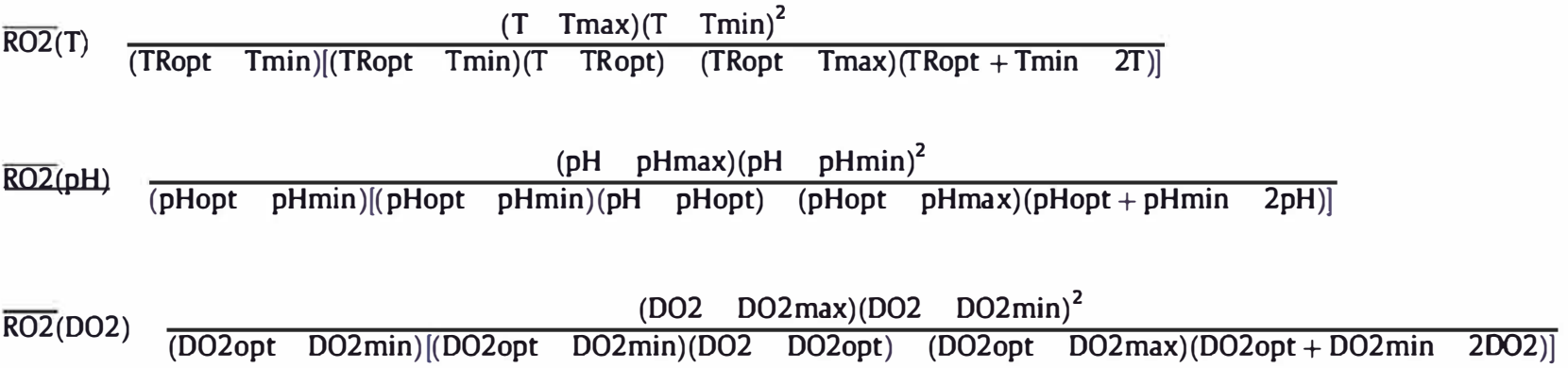

The proposed equations allows us to modeled the photosynthe sis and respiration rates as a function of the culture conditions the cells are exposed to inside the culture over a short period, but possibly conditions that are not supported over long periods, or
In order to determine the optimal values of the characteristic parameters included in these models, we performed a non lineal regression of the entire data to the experimental data set. The value of characteristic parameters obtained is shown in Table 1 

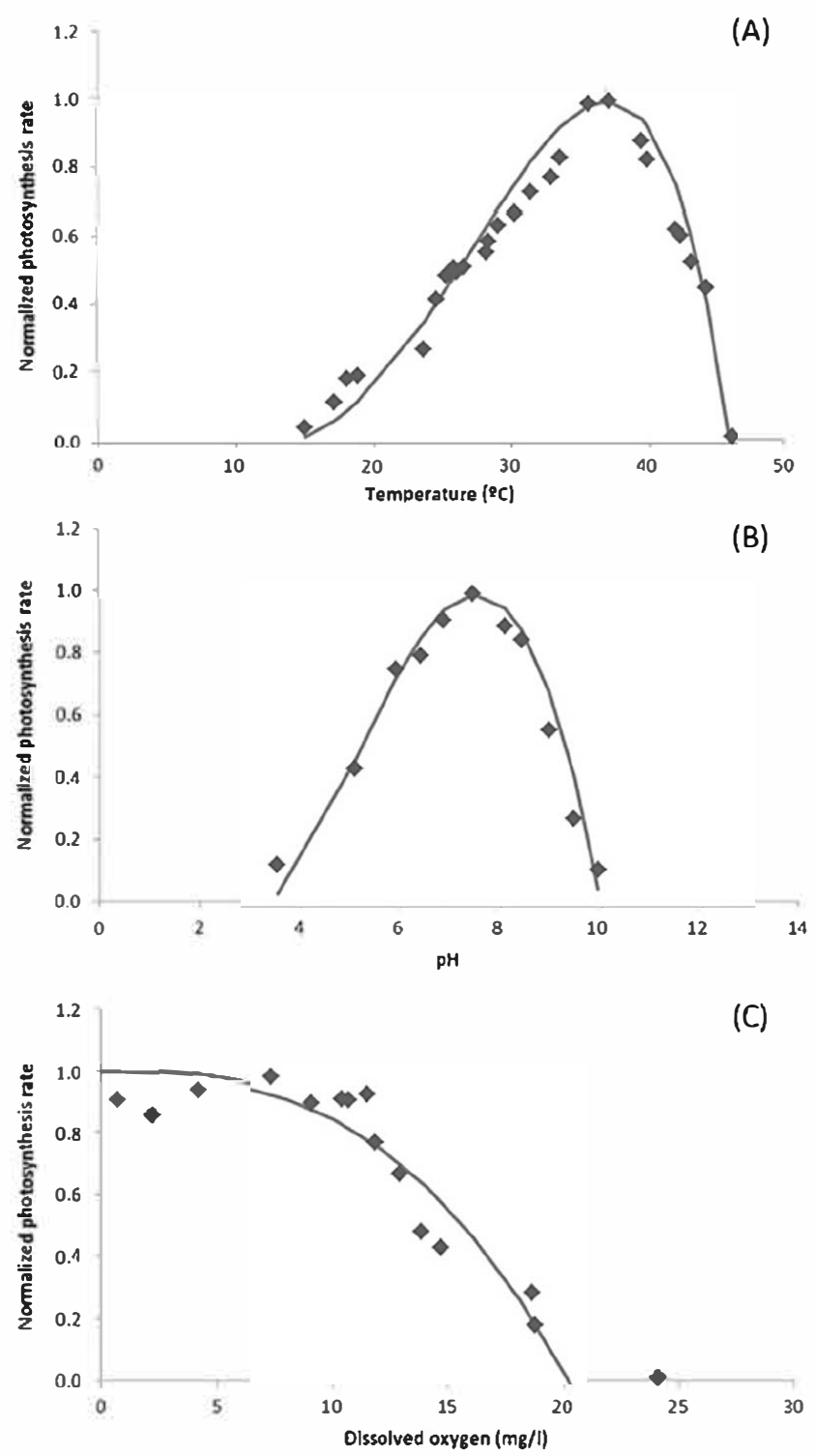

Fig. 2. Influence of temperature (A), pH (B) and dissolved oxygen concentration (C) on the normalized photosynthesis rate of Isochrysis galbana at $600 \mu \mathrm{E} / \mathrm{m}^{2}$ s. Experiments performed under standard conditions for other culture conditions $\left(29^{\circ} \mathrm{C}, \mathrm{pH}=7.5\right.$ and $\left.\mathrm{DO} 2=7.6 \mathrm{mg} / \mathrm{l}\right)$. Lines correspond to fit the proposed models (Eqs.

$(3-5)$ )

whereas the correlation between experimental and simulated values obtained using the proposed model (Eqs. $\left(\begin{array}{ll}1 & 10\end{array}\right)$ ) and the characteristic parameter values obtained is shown in Fig. 5. One can observe how the proposed model simulates the experimental values of the net photosynthesis and respiration rates; with the correlation for the net photosynthesis rate being even higher than that for the respiration rate. According to these results, it is demonstrated that the developed model reproduces the photosynthesis and respiration rates of Isochrysis not only for short time periods (minutes) but also for long periods (up to two hours); thus making them sufficiently robust to be exposed to real outdoor conditions where changes in the culture conditions, especially temperature, take place slowly in line with the solar cycle.

\subsection{Application of the photosynthesis rate model to industrial scale T PBRs}

The model has been validated to study the performance of $l$. galbana cultures grown in an industrial scale tubular photobioreactor.
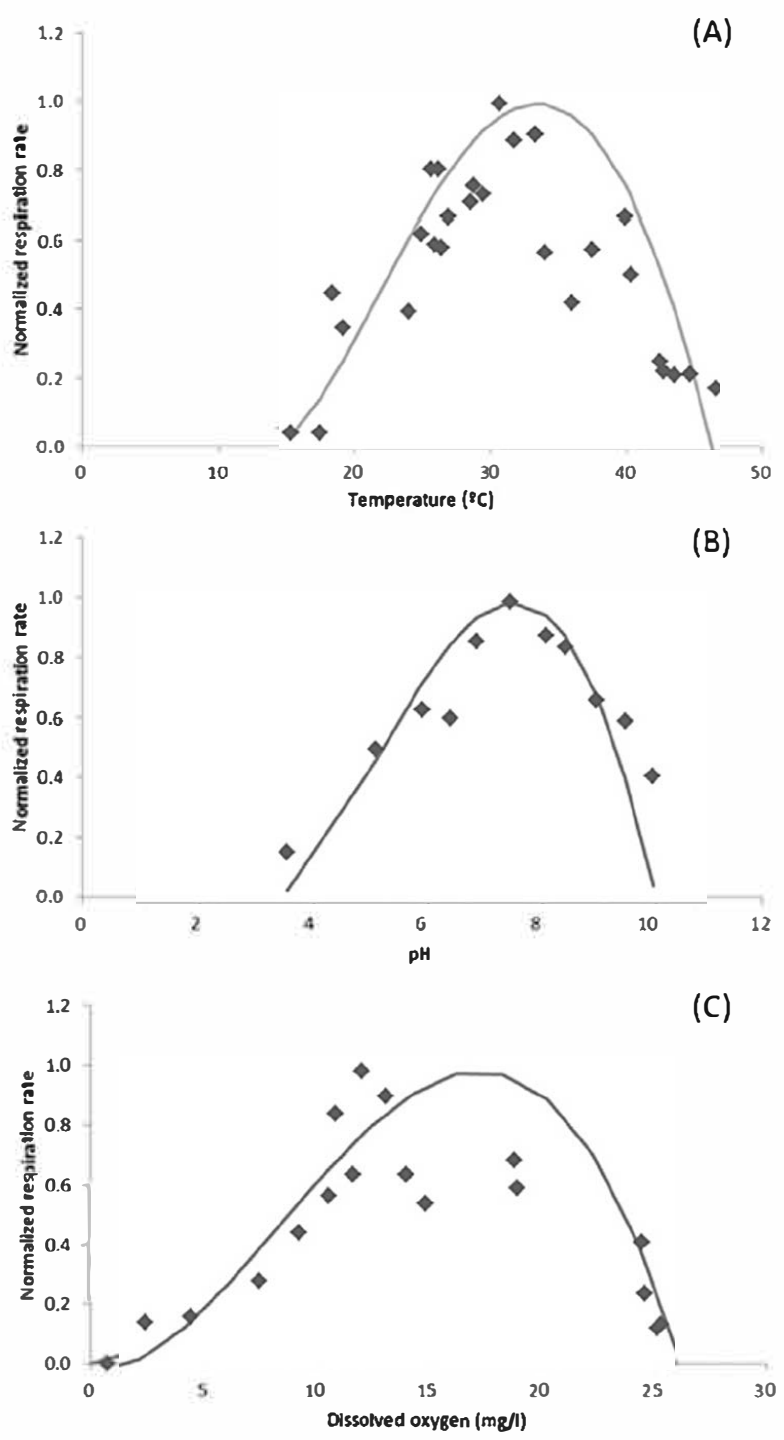

Fig. 3. Influence of temperature (A), pH (B) and dissolved oxygen concentration (C) on the normalized respiration rate of Isochrysis galbana. Experiments performed under standard conditions for other culture conditions $\left(29^{\circ} \mathrm{C}, \mathrm{pH}=7.5\right.$ and $\mathrm{DO2}=$ $7.6 \mathrm{mg} / \mathrm{l}$ ). Lines correspond to fit the proposed models (Eqs $(6-8)$ ).

For this, experimental data of the average irradiance, temperature, $\mathrm{pH}$ and dissolved oxygen measured on line in the reactor during a solar cycle in steady state has been used (Fig. 6A). Data show that the average irradiance inside the culture ranges daily from zero to $1000 \mu \mathrm{E} \mathrm{m}{ }^{2} s^{1}$ confirming that the cells are mainly light limited, even at noon when there is high solar irradiance (up to 1600 $\mu \mathrm{E} \mathrm{m}{ }^{2} \mathrm{~s}^{1}$ ). Moreover, during the solar cycle, the temperature ranges from $19.0^{\circ} \mathrm{C}$ to $29.7^{\circ} \mathrm{C}$, whereas the $\mathrm{pH}$ varies from 7.6 to 8.1 , and the dissolved oxygen from 5.1 to $14.4 \mathrm{mg} \mathrm{l}{ }^{1}$. These values are close to those previously reported for outdoor cultures of Isochrysis in outdoor photobioreactors (van Bergeijk et al., 2010; Zhang and Richmond, 2003). Concerning temperature variation, this modifies by up to $10^{\circ} \mathrm{C}$, according to the solar cycle, because the control system only allows us to avoid overheating of the culture inside the reactor. Furthermore, the average value was $24.3^{\circ}$ C, far from the optimal photosynthesis rate value deter mined at $36^{\circ}$ C (Fig. 2A) but close to the previously reported opti mal rate, at $21^{\circ}$ $C$ (van Bergeijk et al., 2010). The temperature effect is very important on outdoor microalgal cultures subject to daily culture condition variations (particularly irradiance and tempera ture) for which simultaneous adverse conditions can take place 

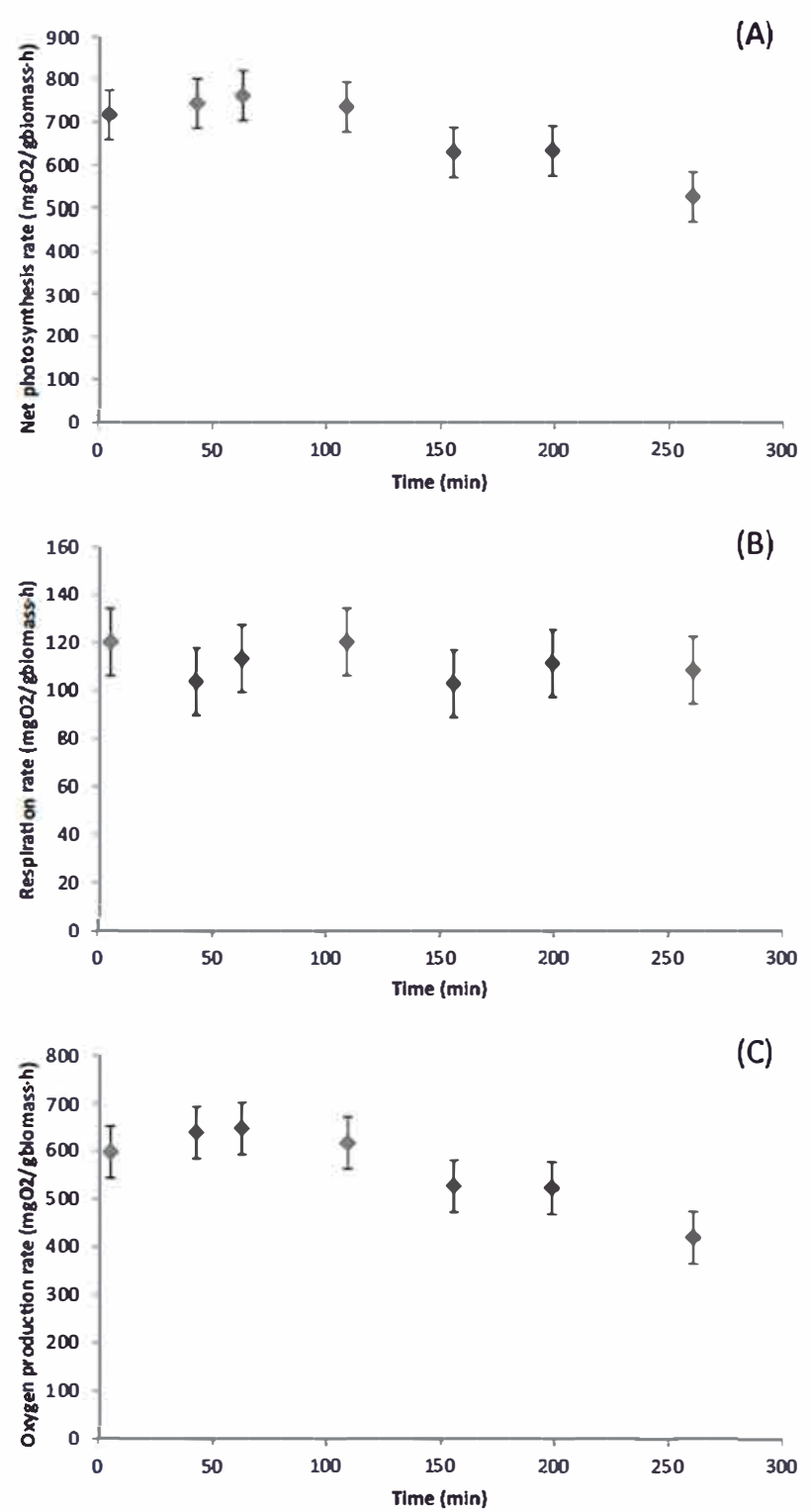

Fig. 4. Variation in the net photosynthesis rate (A), respiration rate (B) and oxygen production rate (C) with time for Isochrysis galbana cells exposed to high temperature $\left(35^{\circ} \mathrm{C}\right)$ for a long period. Measurements performed under the standard culture conditions $\left(l=600 \mu \mathrm{E} / \mathrm{m}^{2} \mathrm{~s}, \mathrm{pH}=7.5, \mathrm{DO}_{2}=10 \mathrm{mg} / \mathrm{l}\right)$

(van Bergeijk et al., 2010). The negative effect of low temperature and high irradiance has already been demonstrated when occurring in the first hours of the morning in outdoor raceway ponds, with these conditions enhancing the photo inhibition phenomena. The utilization of closed photobioreactors rather than open raceways allows us to improve temperature control, making it possible to increase the night time temperature and to avoid overheating at noon but this involves a higher production cost (Acién et al., 2013b). The variation in $\mathrm{pH}$ is minimal, up to $0.5 \mathrm{pH}$ units, due to the control system's adequacy in supplying $\mathrm{CO}_{2}$ and controlling $\mathrm{pH}$. The average $\mathrm{pH}$ value is 7.9 , close to the optimal value determined for photosynthesis rate of Isochrysis T Iso, of 7.5 (Fig. 2B). Microalgae culture productivity can be influenced not only by the mean $\mathrm{pH}$ value but also by local $\mathrm{pH}$ gradients that take place when pure carbon dioxide is supplied (Femández et al., 2014). The data obtained show the optimal $\mathrm{pH}$ range is between 7.0 and 8.0 therefore to optimize productivity in the T PBRs, it was enough to use the on demand injection of pure $\mathrm{CO}_{2}$ to keep
Table 1

Values for the proposed model's parameter characteristics (Eqs. (1-10)) obtained by non-linear regression of the experimental values of the net photosynthesis rate and respiration rate under the experimental conditions tested.

\begin{tabular}{|c|c|c|c|c|c|}
\hline \multicolumn{3}{|c|}{ Net photosynthesis rate } & \multicolumn{3}{|c|}{ Respiration rate } \\
\hline Parameter & Value & Units & Parameter & Value & Units \\
\hline$a$ & $3.42 E-07$ & & $\mathrm{RO} 2 \mathrm{~min}$ & 52.17 & $\mathrm{mgO}_{2} / \mathrm{lh}$ \\
\hline$b$ & $9.30 E-04$ & & $\mathrm{RO2max}$ & 153.00 & $\mathrm{mgO}_{2} / \mathrm{l} \mathrm{h}$ \\
\hline$c$ & $2.90 E-01$ & & lk & 1152.00 & $\mu \mathrm{E} / \mathrm{m}^{2} \mathrm{~s}$ \\
\hline F02 max & 641.01 & $\mathrm{mgO}_{2} / \mathrm{h}$ & $n$ & 1.90 & \\
\hline Ik & 186.05 & $\mu \mathrm{E} / \mathrm{m}^{2} \mathrm{~s}$ & Tmin & 12.84 & ${ }^{\circ} \mathrm{C}$ \\
\hline Im & 921.23 & $\mu \mathrm{E} / \mathrm{m}^{2} \mathrm{~s}$ & Tmax & 45.82 & ${ }^{\circ} \mathrm{C}$ \\
\hline alfa & 3.45 & & Topt & 33.00 & ${ }^{\circ} \mathrm{C}$ \\
\hline Tmin & 11.88 & ${ }^{\circ} \mathrm{C}$ & pHmin & 3.00 & \\
\hline Tmax & 46.15 & ${ }^{\circ} \mathrm{C}$ & pHmax & 10.00 & \\
\hline Topt & 35.73 & ${ }^{\circ} \mathrm{C}$ & pHopt & 7.50 & \\
\hline pHmin & 2.24 & & DO2min & 0.70 & $\mathrm{mgO}_{2} / \mathrm{l}$ \\
\hline pHmax & 10.00 & & DO2max & 23.27 & $\mathrm{mgO}_{2} / \mathrm{l}$ \\
\hline pHopt & 7.34 & & DO2opt & 11.96 & $\mathrm{mgO}_{2} / \mathrm{l}$ \\
\hline $\mathrm{KO}_{2}$ & 19.99 & $\mathrm{mgO}_{2} / \mathrm{l}$ & & & \\
\hline$z$ & 2.90 & & & & \\
\hline
\end{tabular}
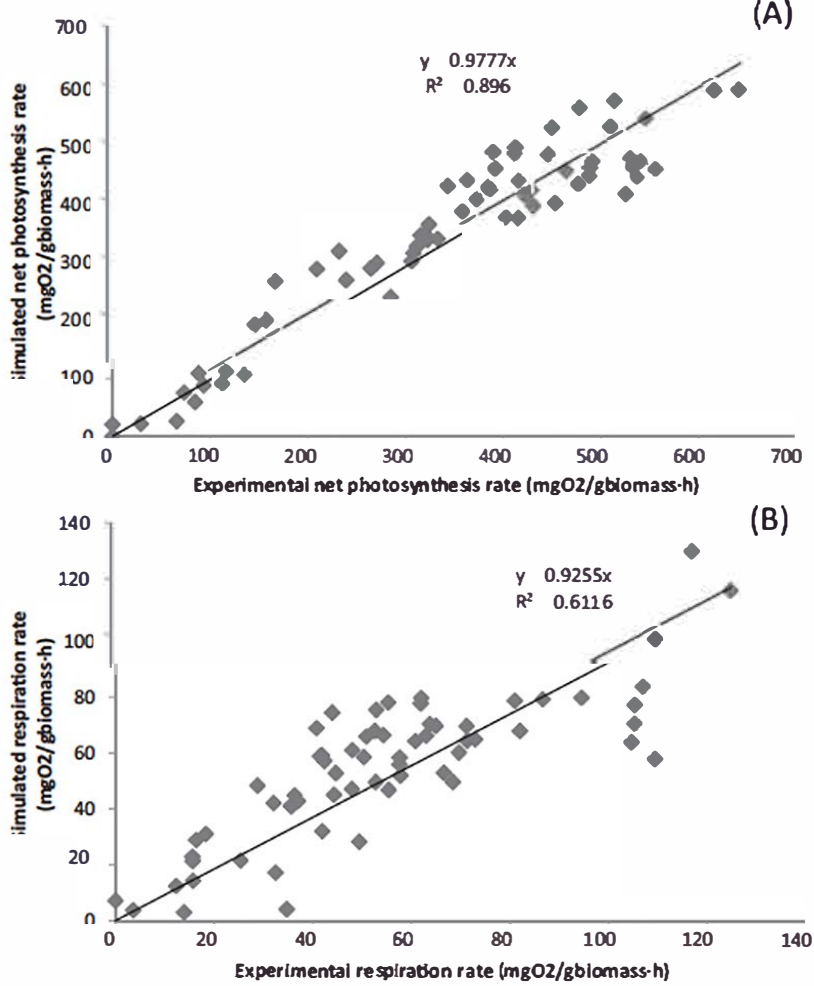

Fig. 5. Correlation between experimental and simulated values of the net photosynthesis rate (A) and respiration rate (B) of Isochrysis galbana. Simulated values obtained using the proposed models (Eqs. (1-10)) and the parameter characteristic values shown in Table 1.

the $\mathrm{pH}$ lower than 8.0. Finally, the average dissolved oxygen con centration was $9.1 \mathrm{mg} \mathrm{I}^{1}$. close to air saturation, but at noon, val ues up to $14.4 \mathrm{mg} \mathrm{l}{ }^{1}$ were measured due to the system's inability to remove all the oxygen produced by photosynthesis. According to the photosynthesis model, dissolved oxygen concentrations above $11 \mathrm{mg} \mathrm{I}{ }^{1}$ reduce cell performance (Fig. 2C), and therefore repre sent a relevant reduction in productivity.

From these experimental values of temperature. $\mathrm{pH}$ and dis solved oxygen, the normalized photosynthesis rate can be calcu lated by Eqs. (3) (5) (Fig. 6B). Results confirm that $\mathrm{pH}$ was adequately controlled and did not reduce the photosynthesis rate, whereas temperature and dissolved oxygen varied greatly through 

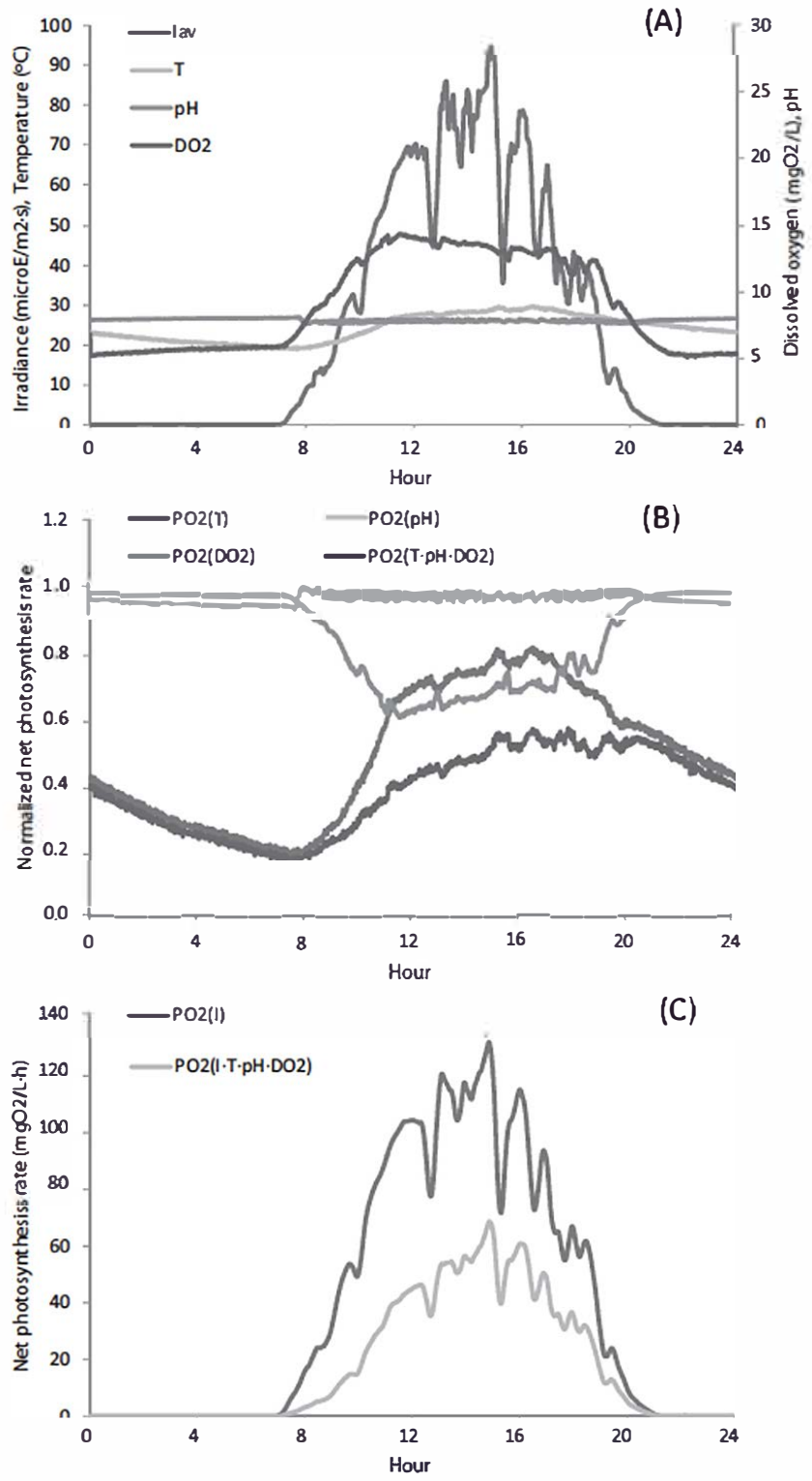

Fig. 6. Daily variation in culture parameters of Isochrysis galbana culture in an industrial-scale tubular photobioreactor operated in continuous mode at $0.41 /$ day. (A) Experimental values of average irradiance, temperature, $\mathrm{pH}$ and dissolved oxygen to which the cells are exposed inside the culture; (B) Influence of culture conditions $\left(\mathrm{T}, \mathrm{pH}, \mathrm{DO}_{2}\right)$ in the normalized photosynthesis rate according to the proposed equations (Eqs. (3-5)); (C) Net photosynthesis rate as a function of irradiance (Eq. (1)) and of all thevariables (I, T, pH, DO2) (Eq. (9)).

the solar cycle, values being far from optimal, and thus the normalized photosynthesis rate was less than maximal. A larger contribution to a reduced photosynthesis rate came from the inadequacy of the culture conditions because of temperature and dissolved oxygen deviations taking place during the light period. The integral of values during the light period was 0.97 for $\mathrm{PO} 2$ $(\mathrm{pH})$, whereas it was 0.61 for PO2(T) and 0.77 for PO2(DO2). These results indicate that the photosynthesis rate can be increased $39 \%$ by optimizing the temperature control and $27 \%$ by optimizing the dissolved oxygen concentration inside the culture thus photosynthesis can be more than doubled by optimizing both parameters at the same time ( $\mathrm{PO} 2(\mathrm{~T} \mathrm{pH} \mathrm{DO2}$ ) being 0.44 ).

To better understand these phenomena, Fig. $6 \mathrm{C}$ shows the expected photosynthesis rate based on average irradiance inside the culture (considering optimal values of temperature, $\mathrm{pH}$, and dissolved oxygen) (Eq. (1)), and calculated considering all the culture conditions (irradiance, temperature, $\mathrm{pH}$ and dissolved oxygen) (Eq. (9)). It can be observed that net photosynthesis, as a function solely of irradiance (PO2 $(I)$ ), is much higher than that calculated when considering all the culture parameters (PO2 $(I \mathrm{~T}$ $\mathrm{pH}$ DO2 )), especially at noon when light availability is maximal. Thus, the integral of $\mathrm{PO} 2(I)$ values allows us to calculate the maximal oxygen production, $0.92 \mathrm{~g} \mathrm{O}_{2} \mathrm{l}^{1}$ day ', whereas the integral of $\mathrm{PO} 2(I \mathrm{~T} \mathrm{pH} \mathrm{DO2})$ allows us to calculate the real oxygen produc tion, $0.42 \mathrm{~g} \mathrm{O}_{2} \mathrm{l}^{1}$ day ${ }^{1}$. In this way, it is confirmed that the photosynthesis rate can be doubled by optimizing the control of the culture conditions in the reactors used. Moreover, by compar ing the real oxygen production, calculated using the proposed model, with the experimental biomass productivity measured, of 0.22 gbiomass ${ }^{1}$ day ${ }^{1}$. the oxygen to biomass ratio can be calcu lated a value of $1.94 \mathrm{~g} \mathrm{O}$ gbiomass. USEPA (1985) quotes oxygen yield values from various studies for algal biomass production from 1.24 to $1.80 \mathrm{~g} \mathrm{O}_{2}$

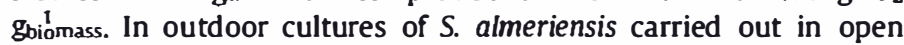
raceway reactors, an oxygen to biomass ratio of $1.46 \mathrm{~g} \mathrm{O}_{2} \mathrm{~g}_{\mathrm{b}}{ }^{1}$ mass was measured when using flue gas to control $\mathrm{pH}$ and to supply $\mathrm{CO}_{2}$; whereas a ratio of $0.99 \mathrm{~g} \mathrm{O}_{2}$ gbiomass was measured when using pure $\mathrm{CO}_{2}$ (Mendoza et al., 2013 ). The oxygen yield value reported here agrees with that previously reported, thus confirming the proposed model's validity in determining oxygen production as a function of culture conditions; and, moreover, loss of productivity due to deviation in the culture conditions. It is therefore a useful tool for taking decisions regarding the implementation of different control strategies.

\section{Conclusions}

Irradiance, temperature, $\mathrm{pH}$ and dissolved oxygen are relevant variables determining the performance of Isochrysis $T$ iso cultures. We have developed a complete photosynthesis and respiration rate model for Isochrysis $T$ iso based on these variables. The model's validity was verified outdoors using industrial scale tubular photobioreactors. The model allowed us to determine that inadequate temperature and dissolved oxygen in the outdoor tubular photo bioreactors reduce productivity by half that of the maximal level according to light availability. The developed model is a power tool for the design and management of Isochrysis $T$ iso based outdoor processes, to take decisions about the implementation of profitable control strategies.

\section{Acknowledgements}

This research was supported by the Erasmus+ traineeship pro gramme of the Università di Bologna and the CO2ALGAEFIX project (LIFE10 ENV/ES/000496) led by AlgaEnergy company. We are most grateful to the Estación Experimental Las Palmerillas of the Fun dación Cajamar for collaborating in this research. This research was supported by the Junta de Andalucia and the Plan Andaluz de Investigación (B1O 173).

\section{References}

Acién, F.G., Fernández, J.M., Molina, E., 2013a. Photobioreactors for the production of microalgae. Rev. Environ. Sci. Biotechnol., 1-21 Acién, F.G., Fernández, J.M., Molina-Grima, E., 2013b. Economics of microalgae biomass production Biofuels Algae, 313-325.

Badger, M.R., Von Caemmerer, S. Ruuska, S., Nakano, H., Laisk, A., Allen. J.F., Asada. K., Matthijs, H.C.P., Griffiths, H., 2000. Electron flow to oxygen in higher plants and algae: Rates and control of direct photoreduction (Mehler reaction) and rubisco oxygenase. Philos. Trans. R. Soc. B Biol. Sci. 355, 1433-1446.

Bemard, O., Rémond, B., 2012. Validation of a simple model accounting for light and temperature effect on microalgal growth. Bioresour. Technol. 123, 520-527.

Bitaubé, E., Caro, I., Pérez, L. 2008. Kinetic model for growth of Phaeodactylum tricomutum in intensive culture photobioreactor. Biochem. Eng. J. 40, 520-525. 
Blanchard, G.F., Guarini, J., Richard, P., Gros, P., Mornet, F., 1996. Quantifying the short-term temperature effect on light-saturated photosynthesis of intertidal microphytobenthos. Mar. Ecol. Prog. Ser. 134, 309-313.

Boeing, P., 2000. Larval feed alternatives. Global Aquaculture Advocate 3 (1), 48-50.

Cabello, J., Toledo-Cervantes, A., Sánchez, L, Revah, S., Morales, M., 2015. Effect of the temperature, $\mathrm{pH}$ and irradiance on the photosynthetic activity by Scenedesmus obtusiusculus under nitrogen replete and deplete conditions. Bioresour. Technol. 181, 128-135.

Camacho, F., Acién, F.G., Sánchez, J.A., García, F., Molina, E., 1999. Prediction of dissolved oxygen and carbon dioxide concentration profiles in tubular photobioreactors for microalgal culture. Biotechnol. Bioeng. 62, 71-86.

Claquin, P., Probert, I., Lefebvre, S., Veron, B., 2008. Effects of temperature on photosynthetic parameters and TEP production in eight species of marine microalgae. Aquat. Microb. Ecol. 51, 1-11.

Costache, T.A., Gabriel Acien, F., Morales, M.M., Fernández-Sevilla, J.M., Stamatin, L, Molina, E., 2013. Comprehensive model of microalgae photosynthesis rate as a function of culture conditions in photobioreactors. Appl. Microbiol. Biotechnol. 97, 7627-7637.

Eilers, P.H.C. Peeters, J.C.H., 1988. A model for the relationship between light intensity and the rate of photosynthesis in phytoplankton. Ecol. Model. 42, 199-

215.

Fernández, I., Acién, F.G., Berenguel, M., Guzmán, J.L., 2014. First principles model of a tubular photobioreactor for microalgal production. Ind. Eng. Chem. Res. 53, 11121-11136.

Geider, R.J., Osborne, B.A., 1989. Respiration and microalgal growth: a review of the quantitative relationship between dark respiration and growth. New Phytol

$112,327-341$.

Goldman, J.C., Riley, C.B., Dennett, M.R., 1982. The effect of $\mathrm{pH}$ in intensive microalgal cultures. II. Species competition. J. Exp. Mar. Biol. Ecol. 57, 15-24

Grobbelaar, J.U., Soeder, C.J., 1985. Respiration losses in planktonic green algae cultivated in raceway ponds. J. Plankton Res. 7, 497-506.

Guedes, A.C., Amaro, H.M., Pereira, R.D., Malcata, F.X., 2011. Effects of temperature and $\mathrm{pH}$ on growth and antioxidant content of the microalga Scenedesmus obliquus. Biotechnol. Prog. 27, 1218-1224.

Jeon, Y.C., Cho, C.W., Yun, Y., 2006. Oxygen evolution rate of photosynthetic microalga Haematococcus pluvialis depending on light intensity and quality. Stud. Surf. Sci. Catal. 159, 157-160.

Marchetti, J., Bougaran, G., Le Dean, L., Mégrier, C., Lukomska, E., Kaas, R., Olivo, E. Baron, R., Robert, R., Cadoret, J.P., 2012. Optimizing conditions for the continuous culture of Isochrysis affinis galbana relevant to commercial hatcheries. Aquaculture 326-329, 106-115.

Mendoza, J.L., Granados, M.R., de Godos, I., Acién, F.G., Molina, E., Heaven, S., Banks, C.J., 2013. Oxygen transfer and evolution in microalgal culture in open raceways. Bioresour. Technol. 137, 188-195.
Moisan, J.R., Moisan, T.A., Abbott, M.R., 2002. Modelling the effect of temperature on the maximum growth rates of phytoplankton populations. Ecol. Model. 153, 197-215.

Muller-Feuga, A., 2013. Microalgae for aquaculture: the current global situation and future trends. Handb. Microalgal Cult. Appl. Phycol. Biotechnol., 613-627 Norsker, N., Barbosa, M.J., Vermuë, M.H., Wijffels, R.H., 2011. Microalgal production - A close look at the economics. Biotechnol. Adv. 29, 24-27.

Papadakis, I.A., Kotzabasis, K., Lika, K., 2005. A cell-based model for the photoacclimation and $\mathrm{CO}_{2}$-acclimation of the photosynthetic apparatus. Biochim. Biophys. Acta Bioenerg. 1708, 250-261.

Platt, T., Gallegos, C.L., Harrison, W.G., 1980. Photoinhibition of photosynthesis in natural assemblages of marine phytoplankton. J. Mar. Res. 38, 687-701.

Ras, M., Steyer, J., Bernard, O., 2013. Temperature effect on microalgae: a crucial factor for outdoor production. Rev. Environ. Sci. Biotechnol. 12, 153-164. Renaud, S.M., Thinh, L., Lambrinidis, G., Parry, D.L, 2002. Effect of temperature on growth, chemical composition and fatty acid composition of tropical Australian microalgae grown in batch cultures. Aquaculture 211, 195-214.

Rosso, L, Lobry, J.R., Flandrois, J.P., 1993. An unexpected correlation between cardinal temperatures of microbial growth highlighted by a new model. J. Theor. Biol. 162, 447-463.

Saoudi-Helis, L., Dubacq, J., Marty, Y., Samain, J, Gudin, C, 1994. Influence of growth rate on pigment and lipid composition of the microalga Isochrysis aff. galbana clone T.iso. J. Appl. Phycol. 6, 315-322.

US EPA, 1985. Guideline for deriving numerical national water quality criteria for the protection of aquatic organisms and their uses. National Technica Information Service Accession Number PB85227049. US EPA, Washington, DC, USA.

van Bergeijk, S.A., Salas-Leiton, E., Cañavate, J.P., 2010. Low and variable productivity and low efficiency of mass cultures of the haptophyte Isochrysis aff. galbana (T-iso) in outdoor tubular photobioreactors. Aquacult. Eng. 43, 14-23.

Vejrazka, C., Janssen, M., Benvenuti, G., Streefland, M., Wijffels, R.H., 2013. Photosynthetic efficiency and oxygen evolution of Chlamydomonas reinhardtii under continuous and flashing light. Appl. Microbiol. Biotechnol. 97, 1523-1532.

Ying, K., Gilmour, D.J., Zimmerman, W.B., 2014. Effects of $\mathrm{CO}_{2}$ and $\mathrm{pH}$ on growth of the microalga Dunaliella salina. J. Microb. Biochem. Technol. 6, 167-173.

Yun, Y., Park, J.M., 2003. Kinetic modeling of the light-dependent photosynthetic activity of the green microalga Chlorella vulgaris. Biotechnol. Bioeng. 83, 303311.

Zhang, C.W., Richmond, A., 2003. Sustainable, high-yielding outdoor mass cultures of Chaetoceros muelleri var. subsalsum and Isochrysis galbana in vertical plate reactors. Mar. Biotechnol. 5, 302-310. 